\title{
REDUCING FATAL CHILDHOOD INFECTIONS
}

he importance of Haemophilus influenzae type b (Hib) as a cause of severe infections in young children is not generally appreciated by health care workers outside children's hospitals or the general public. This is probably because severe $\mathrm{Hib}$ disease is largely restricted to young children (at least 90 per cent of cases occur by five years of age), although there have been a number of case series reporting disease in adults, ${ }^{1}$ particularly epiglottitis.

Despite the restricted age group affected, the annual mortality caused by Hib in the US has been calculated as comparable to that of epidemic poliomyelitis in the early $1950 \mathrm{~s}^{3}$ Universal immunisation against Hib disease has been recommended in a number of countries, including the US (since 1985) and Canada. ${ }^{3}$

To assess the value to the Australian community of immunisation, data on the costs of Hib disease (which depends on disease incidence and sequelae) and the efficacy, costs and side-effects of the vaccine (which depends on population characteristics and vaccine type) are needed. Decisions about vaccine delivery (universal vs targeted and timing and number of doses) are also important.

\section{EPIDEMIOLOGY OF HIB DISEASE}

\section{Pattern of Hib disease}

The epidemiology of invasive Haemophilus disease differs markedly in different geographic areas. The most important differences are the total disease incidence, the age distribution and the proportion of epiglottitis, which are inter-related and have important implications.

The highest reported annual incidence of invasive Haemophilus disease in the world is that in Central Australian Aboriginal children (900 per 100,000 children under five years). Epiglottitis rarely occurs in these groups, in whom most cases occur in the first six months of life, affecting up to 2 per cent of children by their first birthday.

Population-based data on childhood Hib disease show a pattern of Hib disease in urban Australia which resembles that in Scandinavia most closely, with an annual incidence of 30-60 per 100,000 for all Hib disease with a relatively high incidence of epiglottitis (13-23 per 100,000). Using a mid-range estimate of incidence (40), a minimum of 500 cases occur each year in children under five years in Australia.

In a recent study of childhood Hib disease in the greater Sydney metropolitan area, 292 cases in children 0-14 years were identified between 1985 and 1987, an average of about 100 a year. Meningitis accounted for the majority of cases (51 per cent), and epiglottitis ( 32 per cent), with the remainder predominantly cellulitis ( 6 per cent), arthritis ( 5 per cent) and pneumonia ( 4 per cent).

Most studies from the US report a higher incidence for all Hib disease (60-100 per 100,000) but much less epiglottitis (2-11 per 100,000$)^{6}$ This difference in the incidence of epiglottitis largely explains the differences in age distribution, with 50 per cent of cases being over 24 months in Australia ${ }^{5,7}$ and Finland ${ }^{8}$ compared to 20 per cent or fewer in the US. In general, as a higher disease incidence occurs, a lower median age of onset is noted and epiglottitis is found to be relatively less.

Risk factors for Hib disease

Case control studies in the US and Finland have identified day-care outside the home and the presence of young siblings as independent risk factors, whereas breast feeding was protective, ${ }^{9,10,11}$ The interaction of day-care attendance and age differed in two US studies, increasing indirectly with age in Atlanta ${ }^{9}$ but directly with age in Colorado. ${ }^{10}$ The attributable risk for Hib disease from day-care was estimated to be 50 per cent in Atlanta. There is evidence of genetic differences in susceptibility to Hib disease, as well as differences between strains of Hib, but race and ethnicity were not associated with an increased risk of Hib disease after correction for demographic variables in one study.

There are differences in the findings and obvious sociodemographic differences between each area and Australia. Case-control studies are in progress in Sydney and Melbourne to evaluate the importance of these and other risk factors in Australia.

\section{PUBLIC HEALTH IMPORTANCE OF HIB DISEASE}

The magnitude of $\mathrm{Hib}$ as a public health problem depends on its incidence, morbidity and mortality.

\section{Incidence}

The reported incidence of Hib disease in urban Australia varies from 30 per 100,000 in Adelaide, ${ }^{12}$ to 60 in Victoria $^{8}$ and the Gold Coast ${ }^{13}$ and there are also differences in the pattern of disease, with Victoria having a high proportion of epiglottitis. Although some differences may relate to case ascertainment, real differences may exist between urban areas of Australia, in addition to those in rural Aboriginal children, as has been described in New Zealand ${ }^{14}$ and the US ${ }^{6}$.

Mortality

Sudden death before hospital admission occurs in both meningitis ${ }^{15}$ and epiglottitis ${ }^{8}$ and thus mortality will be underestimated if only hospital records are used or if autopsies are not expertly performed. In Sydney in 1985-87, an average of two deaths occurred annually, all of which were due to meningitis and occurred before or soon after hospital admission. The case fatality rate may be higher for NSW as a whole, as rapid access to sophisticated medical care, such as is necessary for epiglottitis, is not available in some areas. If the case fatality rates and incidence of disease observed in Victoria ${ }^{8}$ and Sydney ${ }^{5}$ are projected to Australia, a minimum of 13 deaths are estimated to occur each year due to childhood Hib disease in this country.

\section{Short-term morbidity}

The short-term morbidity and costs of Hib disease primarily relate to hospitalisation. In Sydney in 1985-87, the mean number of hospital days for meningitis was 15 , epiglottitis 5 , arthritis 11 and other foci 5 , with meningitis accounting for 71 per cent and epiglottitis 16 per cent of the 2916 bed days over this period. However, epiglottitis accounted for more than two-thirds of the 416 intensive-care bed days, whose crude cost is about three times greater than standard hospital days.

\section{Long-term morbidity}

The only published Australian study of post-meningitis morbidity is about 15 years old, included only 14 patients and suggested that significant morbidity was uncommon. ${ }^{16}$ However, preliminary follow-up data from the 138 surviving patients with meningitis in Sydney in 1985-87 indicate otherwise.

Major morbidity (retardation, profound deafness, hydrocephalus) occurred in 7 per cent of children and less severe deficits (fits, motor problems, unilateral hearing loss) in a further 13 per cent. Learning deficits, behaviour problems and other "soft" neurological problems were not studied.

\section{HIB VACCINE EFFICACY}

Four vaccines produced by four different manufacturers, with the Hib capsular polysaccharide (PRP) conjugated to a different protein, are at or near marketing stage in the US. The protein carriers are diphtheria toxoid (PRP-D), a mutant diphtheria toxin (PRP-CRM), an outer membrane 


\section{Reducing Fofal Childhood Infections}

\section{Continued from page 54}

protein of Neisseria meningitidis (PRP-OMP) and tetanus toxoid (PRP-T). ${ }^{17}$ The former two vaccines are licensed in the US for use at six months of age; the latter two, which may be more immunogenic in the first six months of life, are likely to be licensed there soon. An additional advantage of the conjugate vaccines is that children who have developed Hib disease despite receiving PRP vaccine appear to respond to them..$^{18}$

The efficacy of vaccines has been controversial because of widely varying observations, first with PRP vaccine and more recently with the conjugate vaccines. ${ }^{19}$ The only large trials have been conducted in Finland, where the most recent results from a trial using PRP-D give an efficacy of 94 per cent (CI 83-98 per cent) among children 7-24 months after vaccine at $3,4,6$ and 18 months. ${ }^{20}$ This vaccine has been used routinely in Finland since 1988, with a decrease in cases of Hib disease among children under five years from 172 in 1986 to 27 in $1989^{20}$

PRP-D vaccine in Alaska had an efficacy of only 37 per cent ${ }^{19}$ although the calculated number of children required to vaccinate with PRP-D to prevent one case of invasive Hib disease in Alaska (270) was much fewer than Finland (2410) because of the high incidence of disease there ( $1000 \mathrm{per}$ $100,000$ vs 50 per 100,000$)^{19}$

\section{VACCINE SIDE-EFFECTS}

There are extensive data documenting the safety of PRP vaccine in the US. ${ }^{21} \mathrm{~A}$ Finnish study has shown that PRP-D retains its immunogenicity when given with triple antigen and is associated with a similar incidence of side-effects to triple antigen alone ${ }^{22}$ The main concern is the induction of a transient fall in antibody levels which has been documented with both the PRP and conjugated vaccines. ${ }^{23}$ Although this may be associated with a short period of enhanced susceptibility to invasive disease, it is not a significant consideration except in the special situation of an outbreak of Hib disease (eg a day-care centre) where chemoprophylaxis rather than vaccination is indicated, at least initially.

\section{VACCINE COSTS}

Vaccine administration differs markedly between States, which can have a substantial impact on costs. However these costs are largely fixed, and as any $\mathrm{Hib}$ vaccine could be given within the current schedule, additional administration costs should be minimal. Two cost analyses of PRP vaccine at two years ${ }^{24,25}$ and one of PRP-D vaccine at 18 months $^{26}$ in the US concluded that immunisation was cost-effective. In Australia, the pattern of an older disease peak and greater public funding of vaccination would be expected to make the equation more favourable. The cost of prevention of Hib disease should be put in the context of other potentially vaccine-preventable diseases, such as hepatitis B and varicella, when decisions about funding priorities are made.

\section{CONCLUSIONS}

Invasive Hib disease is a common cause of serious morbidity and mortality in Australian children, with an estimated minimum of 500 cases and 13 deaths annually.

Protein conjugate vaccines are among the safest. They appear to be highly immunogenic, however good-quality data on effectiveness are available only from Finland and substantial differences may exist between populations in their response to polysaccharide vaccines. One of these conjugate vaccines has recently been licensed for use at two four and six months in the US; licensing of two such vaccines in Australia is being reviewed.

For vaccination against $\mathrm{Hib}$ to be effective as a public health measure, it should be introduced in a co-ordinated fashion after consideration of the various competing alternatives, the most prominent of which is vaccination against hepatitis $B$. Detailed consideration of the costs and benefits of universal as opposed to directed immunisation and specific vaccination schedules, both timing and number of doses, in the context of Australian data is needed.

\section{Peter McIntyre \\ Department of Paediatrics \\ Westmead Hospital}

1. Trollfors B, Claesson B, Lagergard T, Sandberg T, Incidence, predisposing factors and manifestations of invasive Haemophilus influenzae infections in adults, Eur J Clin Microbiol 1984:3:180-4

2. Trollfors $B$, Nylen $O$ Strangert $K$, Acute epiglottitis in children and adults in Sweden 1981-83, Arch Dis Child 1990;65:491-94

3. Cochi SL, O'Mera B, Preblud SR, Progress in Haemophilus type b

polysaccharide vaccine use in the United States, Pediatr 1988;81:166-168.

4. Hanna J, The epidemiology of invasive Haemophilus influenzae infections in children under five years of age in the Northern Territory: a three-year study, Med J Aust 1990;152:234-40.

5. McIntyre P, Leeder SR, Irwig L, Invasive Haemophilus infiuenzce type b disease in Sydney children 1985-8: a population-based study submitted for publication. 6 . Broome CV, Epidemiology of Haemophilus influenzae type b infections in the United States, Pediatr Inf Dis $J$ 1987;6:779-82

7. Takala AK, Eskola J, Peltola H, Makela AH, Epidemiology of invasive Homphilus influenzae type b disese among children in Finland before vecination with Haemophilus influenae type b conjugate vaccine Pedio vaccination with Haemop $J$ 1989:8-297-302.

8. Gilbert GL, Clements DA, Broughton S.J, Haemophilus influenzae type b 8. Gilbert GL, Clements DA, Broughton SJ, Haemophilus influenzae type b infections in Victoria, Australia, 1985 to 1987 , Pediatr Inf Dis J 1990;9:252-7. 9. Cochi SL, Fleming DW, Hightower AW, et al, Primary invasive Haemoph influenzae type b disease:

J Pediatr 1986;108:887-96.
10. Istre GR, Conner JS, Broome ECV, Hightower A, Hopkins RS, Risk factor 10. Istre GR, Conner JS, Broome ECV, Hightower A, Hopkins RS, Risk factors
for primary invasive Haemophilus influenzae disease: Increased risk from daycare attendance and school-aged household members. J Pediatr 1984;106:190-95 11. Takala AK, Epidemiologic characteristics and risk factors for invasive Haemophilus influenzae type b disease in a population with high vaccine efficacy, Pediatr Infect Dis $J$ 1989;8:343-6.

12. Hansman D, Hanna J, Morey F, High prevalence of invasive Haemophilus influenzae disease in Central Australia 1986, Lancet 1986;(ii)927.

13. Booy R, Price D, Invasive Haemophilus disease: a provincial perspective, Abstract. Australian College of Paediatrics Scientific Meeting 1989.

14. Voss $\mathrm{L}$, Lennon D, Gillies M, Haemophilus influenzae type b disease in Auckland children 1981-7, NZ Med I 1989;102:149-51.

15. Goldacre MJ Acute bacterial meningitis in childhood, Lancet 1976:(i)28-31. 15. Goldacre MJ, Acute bacterial meningitis in childhood, Lancet 1976;(1) 16. Emmett M, Jeffey H, Chander D, Dugdale AL,

influenzae meningitis, Aust Paediatr J 1980;16:90-93.
17. Robbins JB, Schneerson R, Haemophilus influenzae type b: the search for 17. Robbins JB, Schneerson R, Haemophil

a vaccine, Pediatr Inf $D$ is $J 1987 ; 6: 791-$

18. Anderson P, Insel RA, Prospects for overcoming maturational and genetic barriers to the human antibody response to the capsule polysaccharide of Haemophilus influenzae type b Vaccine 1988;6:188-91.

19. Steib DM, Frayha HH, Oxman AD, Shannon HS, et al, Effectiveness of Haemophilus influenzae type b vaccines, Can Med Assoc J 1990;142:719-32. 20. Eskola J, Kayhty H, Takala A, Peltola H, et al, A randomised, prospective field trial of a conjugate vaccine in the protection of infants and young children against invasive Haemophilus influenzae type b disease, $N$ Eng $J M$ 1990;323:1381.87. 21. Milstein JB, Gross TP, Kuritsky JW, Adverse reactions reported following recin of $H$. receipt for Haemophilus influenzae type

of marketing, Pediti $197,8,270.74 . \quad 1$ Simultane 22. Eskola J, Kayhty capsular polysaccharide - diphtheria toxoid conjugate vaccine with routine diphtheria-tetanus-pertussis and inactivated coliovirus vaccinations of child hood, Pediatr Irf Dis J 1988;7:480-84.

23. Daum RS, Sood SK, Osterholm MT, Pramberg JC, et al, Decline in serum antibody to the capsule of Hoemophilus infiuenzae type b in the immediate post-immunisation period, $J$ Pediatr 1989:114:742-47.

24. Cochi SL, Broome CV, Hightower AW, Immunisation of US children with Haemophilus influenzae type b polysaccharide vaccine. A cost effectiveness model of strategy assessment, JAMA 1985;253:521-529.

25. Hay JW, Daum RS, Cost-benefit analysis of two strategies for prevention of Haemophilus influenzae type be infection, Pediatr 1987;80:319-29.

26. Hay JW, Daum RS, Cost-benefit analysis of Haemophilus influenzae type b prevention: conjugate vaccination at 18 months of age, Pediatr Inf Dis $J$ 1990:9:246-52 